\title{
The impact of polar stratospheric ozone loss on Southern Hemisphere stratospheric circulation and climate
}

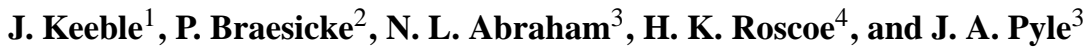 \\ ${ }^{1}$ Chemistry Department, University of Cambridge, Cambridge, UK \\ ${ }^{2}$ Karlsruhe Institute of Technology, Institute for Meteorology and Climate Research, Karlsruhe, Germany \\ ${ }^{3}$ NCAS/University of Cambridge, Chemistry Department, Cambridge, UK \\ ${ }^{4}$ British Antarctic Survey, NERC, Cambridge, UK \\ Correspondence to: J. Keeble (jmk64@ cam.ac.uk)
}

Received: 29 May 2014 - Published in Atmos. Chem. Phys. Discuss.: 3 July 2014

Revised: 11 November 2014 - Accepted: 18 November 2014 - Published: 22 December 2014

\begin{abstract}
The impact of polar stratospheric ozone loss resulting from chlorine activation on polar stratospheric clouds is examined using a pair of model integrations run with the fully coupled chemistry climate model UM-UKCA. Suppressing chlorine activation through heterogeneous reactions is found to produce modelled ozone differences consistent with observed ozone differences between the present and pre-ozone hole period. Statistically significant high-latitude Southern Hemisphere (SH) ozone loss begins in August and peaks in October-November, with $>75 \%$ of ozone destroyed at $50 \mathrm{hPa}$. Associated with this ozone destruction is a $>12 \mathrm{~K}$ decrease of the lower polar stratospheric temperatures and an increase of $>6 \mathrm{~K}$ in the upper stratosphere. The heating components of this temperature change are diagnosed and it is found that the temperature dipole is the result of decreased short-wave heating in the lower stratosphere and increased dynamical heating in the upper stratosphere. The cooling of the polar lower stratosphere leads, through thermal wind balance, to an acceleration of the polar vortex and delays its breakdown by $\sim 2$ weeks. A link between lower stratospheric zonal wind speed, the vertical component of the Eliassen-Palm (EP) flux, $F_{z}$ and the residual mean vertical circulation, $\bar{w}^{*}$, is identified. In November and December, increased westerly winds and a delay in the breakup of the polar vortex lead to increases in $F_{z}$, indicating increased wave activity entering the stratosphere and propagating to higher altitudes. The resulting increase in wave breaking, diagnosed by decreases to the EP flux divergence, drives enhanced downwelling over the polar cap. Many of the stratospheric signals modelled in this study propagate down to the
\end{abstract}

troposphere, and lead to significant surface changes in December.

\section{Introduction}

The annually recurring Antarctic ozone hole is one of the most conspicuous examples of mankind's impact on the earth system, and as such has received a great deal of scientific study. It is now well established that spring time chemical ozone loss in the polar lower stratosphere is the result of a combination of two processes: stable vortex conditions, which lead to very low temperatures within the vortex and enable the formation of polar stratospheric clouds (PSCs), and increased anthropogenic emissions of ozone depleting substances (ODSs) (WMO, 2011). More recently it has also become apparent that the ozone hole has had significant impacts on stratospheric temperatures, atmospheric circulation and surface climate (e.g. Thompson and Solomon, 2002; Polvani et al., 2011).

Since the discovery of the Antarctic ozone hole in the mid1980s (Farman et al., 1985) rapid advances in the understanding of the causes of high-latitude stratospheric ozone depletion have taken place. The large Southern Hemisphere (SH) spring time ozone losses documented since the mid-1980s result from increased emissions of anthropogenic chlorofluorocarbons (CFCs) combined with unique meteorological conditions at high southern latitudes. Throughout the latter half of the 20th century, the use and emission of CFCs led to an increase of $\sim 3 \mathrm{ppbv}(\sim 400 \%)$ in the total amount of 
chlorine in the stratosphere between 1960 and 2000 (WMO, 2011). The effects of this increased chlorine loading have been small on a global scale, leading to a global average depletion of $3-4 \%$ of the total ozone column. However, over Antarctica, due to heterogeneous chemistry occurring on PSCs the depletion is much more severe, with vortex averaged total ozone column in October $40 \%$ below 1980 values (WMO, 2011).

For typical stratospheric mixing ratios of $\mathrm{HNO}_{3}$ and $\mathrm{H}_{2} \mathrm{O}$, PSC particles form when temperatures fall below $195 \mathrm{~K}$, which is the case for much of the winter over Antarctica. PSCs lead to large decreases in high-latitude, lower stratospheric ozone mixing ratios through two processes. Firstly, these particles act as surfaces where chlorine activation can occur, converting the chlorine reservoir species $\mathrm{HCl}$ and $\mathrm{ClONO}_{2}$ into $\mathrm{Cl}_{2}$ (e.g. Solomon et al., 1986). $\mathrm{Cl}_{2}$ photolysis exists throughout winter in the vortex edge region (e.g. Schoeberl et al., 1992; Lee et al., 2001), but only occurs in the vortex core when sunlight returns in spring, and the resulting chlorine radicals destroy ozone through catalytic cycles (e.g. Molina and Molina, 1987). Secondly, as the particles sediment out, they deplete $\mathrm{NO}_{\mathrm{y}}$ in the lower stratosphere (Toon et al., 1986). This process of denitrification prevents the reformation of the reservoir species until the collapse of the polar vortex, prolonging the period of ozone destruction. The development of a strong, stable vortex around Antarctica during SH winter and spring isolates air over the pole and prevents mixing between high- and mid-latitude air masses (e.g. Tuck, 1989; Schoeberl and Hartmann, 1991; Waugh and Polvani, 2010), which allows for very high levels of chemical ozone depletion. The Arctic vortex is not as stable as that of the Antarctic due to increased planetary wave activity in the Northern Hemisphere (NH), and is often not centred on the cold pole. This limits the volume of air in which PSCs can form, and the amount of time over which they persist, preventing regular large-scale NH ozone loss. As such, this study focuses on the impact of stratospheric ozone depletion on SH climate and circulation. For a full review of stratospheric ozone depletion, see Solomon (1999) and references therein.

Coincident with the development of the annually recurring ozone hole have been significant changes to SH climate. Analysis of radiosonde measurements (Thompson and Solomon, 2002) has shown that from 1970 to 2000 the SH spring time lower stratosphere cooled significantly, reaching a maximum cooling of $6-10 \mathrm{~K}$ in November. This cooling persists through SH summer and autumn, although with a reduced magnitude (1-2 K), with no statistically significant trend observed during SH winter. While the lower stratosphere has cooled, during SH spring statistically significant warming is observed at $30 \mathrm{hPa}$. It should be noted that the trends presented in Thompson and Solomon (2002) are averaged over a number of radiosonde stations, most of which are north of $70^{\circ} \mathrm{S}$. Roscoe et al. (2003) present an analysis for measurements made at Halley, the southernmost station, and determine a maximum cooling of $10-18 \mathrm{~K}$ in November, indicating that cooling in the core of the vortex is greater than that presented by Thompson and Solomon.

While analysis of observational data suggests a link between polar ozone depletion and Antarctic climate change, due to changes in other aspects of the atmospheric system, most notably greenhouse gas (GHG) concentrations, observations alone cannot prove causality. Therefore, a number of idealised model studies have attempted to determine the impact of stratospheric ozone loss by separating the effects of ozone depletion and global warming (Gillett and Thompson, 2003; Arblaster and Meehl, 2006; Braesicke et al., 2006; Garcia and Randel, 2008; Perlwitz et al., 2008; Waugh et al., 2009; McLandress et al., 2010; Son et al., 2010; Polvani et al., 2011; Orr et al., 2012a). While the majority of studies have focused on the stratospheric and tropospheric response to ozone depletion, several authors have explored the impacts on the Southern Ocean (Sigmond and Fyfe, 2010; Sigmond et al., 2011). In order to assess the impacts of Antarctic ozone depletion on climate, these studies have either used prescribed ozone climatologies or varied either GHGs or ODSs while keeping the other fixed. Both of these methods come with caveats. Using prescribed ozone fields has the advantage of representing observed ozone differences, but prevents chemistry-climate feedbacks from developing within the model, which are known to be important for a full understanding of the impacts of ozone depletion. This method also results in the chemical ozone field being inconsistent with the model's dynamical and chemical fields. Varying ODS allows chemistry-climate interactions to occur within the model, but affects gas phase chemistry throughout the stratosphere and also changes the concentration of GHGs between the simulations, as CFCs have very high global warming potentials (WMO, 2011).

In this paper we present a method for assessing the climatic impact of polar stratospheric ozone loss by suppressing chlorine activation through reactions occurring on the surface of PSC particles. Using this method we determine the modelled change in ozone that occurs over Antarctica as a consequence of heterogeneous chemistry, and the subsequent impact on SH climate and stratospheric circulation. As with using either prescribed ozone climatologies or varying ODS concentrations, the method used in this paper has several advantages and disadvantages. It has the advantage of leaving the integrations identical except for the simulation of polar stratospheric ozone loss at high latitudes, so that we can be sure that any dynamic and climate responses are due to high-latitude lower stratospheric ozone depletion alone. It also allows the modelled ozone distribution to remain consistent with the flow field and for chemistry-climate and dynamical feedbacks to occur, which are particularly important due to the radiative impact of ozone. However, this method does not result in a stratospheric $\mathrm{Cl}_{\mathrm{y}}$ loading difference between the integrations and therefore will not fully represent historic global ozone depletion, nor capture the effects of in- 
creased CFCs on stratospheric temperature. We do not suggest that this method is better than that used in other studies, but highlight its suitability for studying chemistry-climate interactions in a chemistry climate model.

We present results of a modelling study assessing the impact of high-latitude polar ozone loss on SH climate and stratospheric circulation. In Sect. 2 the chemistry climate model used for this study is discussed, focusing on its handling of heterogeneous chemical processes, and the simulations are outlined. In Sect. 3 we present the impact of chlorine activation on polar ozone, and the effect polar stratospheric ozone depletion has on temperature, zonal winds, geopotential height and downwelling over the polar cap. In Sect. 4 we present a detailed discussion of the physical mechanisms responsible for the changes shown in Sect. 3. Finally we examine the coupling of the stratosphere and troposphere by quantifying the impact of stratospheric ozone loss on surface climate in Sect. 5.

\section{Description of model and simulations}

In order to determine the impact of lower stratospheric ozone loss on SH climate and global circulation, we use version 7.3 of the Met Office's Unified Model HadGEM 3-A configuration (Hewitt et al., 2011) coupled with the United Kingdom Chemistry and Aerosol module (hereafter referred to as UM-UKCA). The model is run using an updated version of the stratospheric chemistry configuration of UM-UKCA described in Morgenstern et al. (2009), at a horizontal resolution of $2.5^{\circ}$ latitude by $3.75^{\circ}$ longitude, with 60 vertical levels and a model top at $\sim 84 \mathrm{~km}$.

For this study, two simulations are considered, named REF2000 and NHC. REF2000 is a 30-year time-slice integration run with perpetual year 2000 boundary conditions, including sea surface temperatures, sea ice extent, and GHG, CFC and aerosol loadings. NHC is identical to REF2000 except that chlorine activation due to heterogeneous reactions on PSC particles is suppressed, preventing large spring time ozone losses in the lower polar stratosphere. In both integrations gas phase ozone loss is treated in the same manner and the total $\mathrm{Cl}_{\mathrm{y}}$ loading is the same. The difference lies in the treatment of the modelled PSCs. While both integrations were run for 30 years, the first 10 years are discarded as spinup time for the model, and climatologies presented here comprise the last 20 years of the model run.

In UM-UKCA, two types of PSC particles are modelled: nitric acid trihydrate (NAT) and mixed NAT/ice polar stratospheric clouds, calculated following Chipperfield (1999) assuming thermodynamic equilibrium with gas-phase $\mathrm{HNO}_{3}$ and $\mathrm{H}_{2} \mathrm{O}$. PSC formation is treated identically in both model integrations and therefore the radiative impacts of the clouds themselves will not change between the two runs, although PSC occurrence could differ between the two integrations as a result of any chemistry climate feedbacks. In REF2000, five heterogeneous reactions occur on PSC particles, activating the chlorine within the reservoir species. These reactions are as follows:

$$
\begin{aligned}
& \mathrm{ClONO}_{2}+\mathrm{H}_{2} \mathrm{O} \rightarrow \mathrm{HOCl}+\mathrm{HNO}_{3} \\
& \mathrm{ClONO}_{2}+\mathrm{HCl} \rightarrow 2 \mathrm{Cl}+\mathrm{HNO}_{3} \\
& \mathrm{HOCl}+\mathrm{HCl} \rightarrow 2 \mathrm{Cl}+\mathrm{H}_{2} \mathrm{O} \\
& \mathrm{N}_{2} \mathrm{O}_{5}+\mathrm{H}_{2} \mathrm{O} \rightarrow 2 \mathrm{HNO}_{3} \\
& \mathrm{~N}_{2} \mathrm{O}_{5}+\mathrm{HCl} \rightarrow \mathrm{Cl}+\mathrm{NO}_{2}+\mathrm{HNO}_{3} .
\end{aligned}
$$

In the NHC simulation, modelled PSC particles are treated as inert in terms of their chemistry. This is achieved by setting the surface area density of type I and II PSC particles to $0 \mathrm{~cm}^{2} \mathrm{~cm}^{-3}$ when calculating the rates of the five heterogeneous reactions listed above. This method is similar to that employed by Karpechko et al. (2013), who prevent PSC formation by fixing the air temperature passed to their heterogeneous chemistry module to $200 \mathrm{~K}$. However, as we allow PSCs to form, we are able to capture the radiative impacts of the clouds themselves, which trap outgoing long-wave radiation (Sloan and Pollard, 1998). The treatment of liquid sulphate aerosols remains identical in both simulations: aerosol background levels are prescribed in both simulations using a perpetual year 2000 aerosol surface area density updated from SPARC (2006), as described by Eyring et al. (2008).

The result of this method is to produce two integrations which differ predominantly in the mixing ratios of ozone in the lower stratosphere at high latitudes. This ozone difference then acts as a driver for any subsequent chemical and/or climatological differences between the two integrations. Chlorine activation through heterogeneous chemistry and the subsequent ozone catalytic loss cycles are nonlinear processes and a threshold value of stratospheric total inorganic chlorine $\left(\mathrm{Cl}_{\mathrm{y}}\right)$ must be reached for these processes to lead to large ozone depletion. Manzini et al. (2003) estimate this threshold value to be $\sim 2.2$ ppbv. Given this, we argue that suppressing chlorine activation on PSCs is, to first order, comparable to running the simulation with 1960 s levels of stratospheric $\mathrm{Cl}_{\mathrm{y}}$ from the point of view of studying Antarctic polar stratospheric ozone loss. We allow the modelled ozone field to respond to changing dynamics and remain consistent with the modelled flow field, unlike experiments in which ozone is prescribed. In this way we preserve chemistry-climate feedbacks between the two runs to fully understand the effects of stratospheric ozone depletion on both climate and circulation.

\section{Stratospheric response to chlorine activation on PSCs}

Results in this study are presented as differences between the monthly mean climatologies of the two simulations. The dif- 


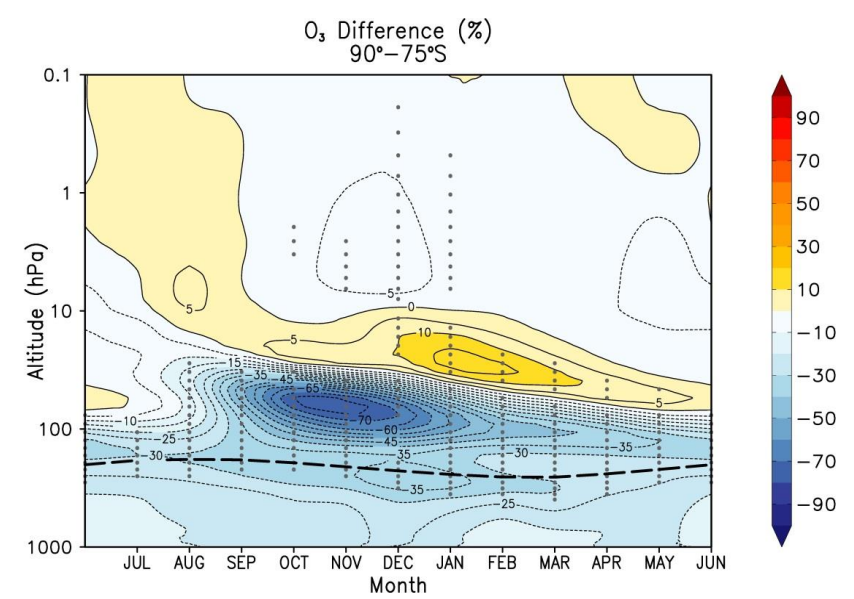

Figure 1. Zonal mean, monthly mean percentage ozone difference between REF2000 and NHC, averaged over $90-75^{\circ}$ S. Contour intervals are $5 \%$; solid/dashed contours represent positive/negative changes. Stippling denotes significance at the $95 \%$ confidence level. The bold dashed line signifies the tropopause height in the REF2000 simulation using a two-tailed Student's $t$ test.

ference is calculated as REF2000-NHC so as to highlight the impact of ozone depletion.

\subsection{Ozone}

The percentage change in monthly, zonal mean ozone between the two integrations, averaged over the polar cap (90$75^{\circ} \mathrm{S}$ ) is shown in Fig. 1. Modelled ozone loss begins in August at approximately $30 \mathrm{hPa}$ and descends in altitude through time, with more than $75 \%$ of ozone destroyed during late October and November at $50 \mathrm{hPa}$. Ozone concentrations in the lower stratosphere remain reduced throughout the summer and autumn. From December to March there is a statistically significant increase in ozone mixing ratios at $20 \mathrm{hPa}$, indicating a change to stratospheric dynamics and an increase in downwelling.

Tropospheric ozone mixing ratios are greatly reduced throughout the year due to a decrease in stratospheretroposphere exchange (STE). However, the version of the model used here does not have a comprehensive tropospheric chemistry scheme and therefore tropospheric ozone changes are not considered in this analysis. For a discussion on the impact of stratospheric ozone changes on STE in UM-UKCA see Morgenstern et al. (2013) and Braesicke et al. (2013).

The timing and vertical extent of the ozone loss are comparable with observed changes in ozone mixing ratios between pre-ozone hole and ozone hole eras (Thompson et al., 2011). However, the maximum modelled ozone loss in late spring is not as great as is observed, where $>90 \%$ loss is seen at $70 \mathrm{hPa}$. This is for two reasons: firstly, there is no increased loss due to gas phase chemistry as the total chlorine burden of the atmosphere is constant between the two simulations. Secondly, the stratospheric chemistry scheme in this

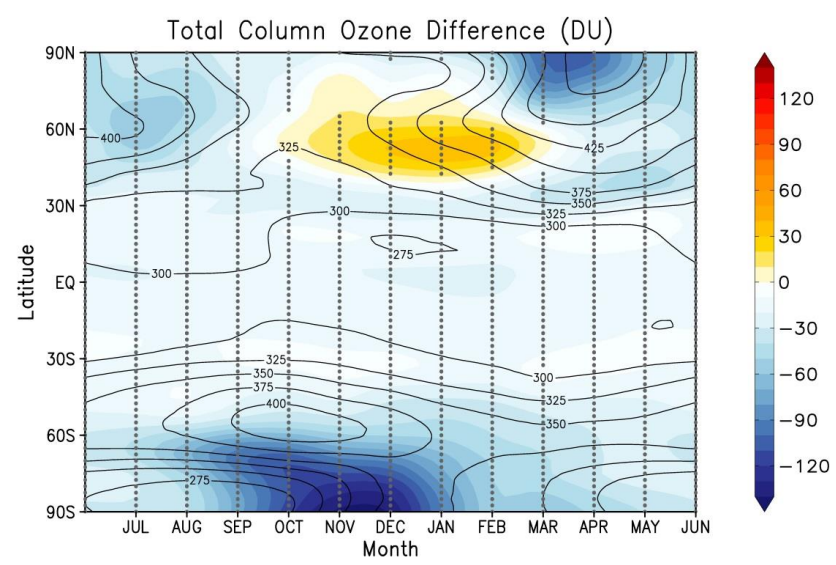

Figure 2. Zonal mean, monthly mean total column ozone REF2000 climatology (contours) and difference between REF2000 and NHC (shaded). Contour intervals are $25 \mathrm{DU}$; stippling denotes significance at the $95 \%$ confidence level.

version of the model does not include heterogeneous reactions involving bromine, the inclusion of which would lead to increased ozone depletion, especially when combined in bromine-chlorine cross-reactions (e.g. McElroy et al., 1986). It should be noted that the observed composite difference presented in Thompson et al. (2011) extends up to $30 \mathrm{hPa}$, and so does not capture the region of increased summer ozone mixing ratios modelled here.

The effects of heterogeneous chemistry on ozone extend beyond the polar vortex. Figure 2 shows the change in global, monthly mean, zonal mean total column ozone between the two simulations, in Dobson Units. While the largest ozone decreases are found in the SH spring time polar vortex, total column ozone over the entire SH has decreased, with decreases of more than $15 \mathrm{DU}$ at the equator. These decreases are statistically significant at the $95 \%$ confidence level at almost all latitudes. In the tropics the decrease in column ozone is the result of decreased lower stratospheric mixing ratios, consistent with an increased Brewer-Dobson circulation (BDC). At higher altitudes (above $\sim 30 \mathrm{hPa}$ ), where the chemical lifetime of ozone is shorter than transport timescales, changes to ozone mixing ratios are minor $(<2 \%)$.

The NH response is more complicated: while column ozone is significantly depleted within the spring time polar vortex, throughout late autumn and winter there is a statistically significant increase in column ozone of $20-30 \mathrm{DU}$ at $\sim 60^{\circ} \mathrm{N}$. This is a noteworthy feature, as the difference in the chemistry between the two integrations (i.e. the activation of chlorine through heterogeneous reactions) can only lead to ozone destruction and should predominantly affect the $\mathrm{SH}$, where PSCs are more abundant. Increased winter column ozone indicates a dynamical response, with increased poleward and downward transport of ozone, suggesting changes to the BDC (after Brewer, 1949; Dobson, 1956). Increased $\mathrm{NH}$ total column ozone values precede Arctic ozone deple- 


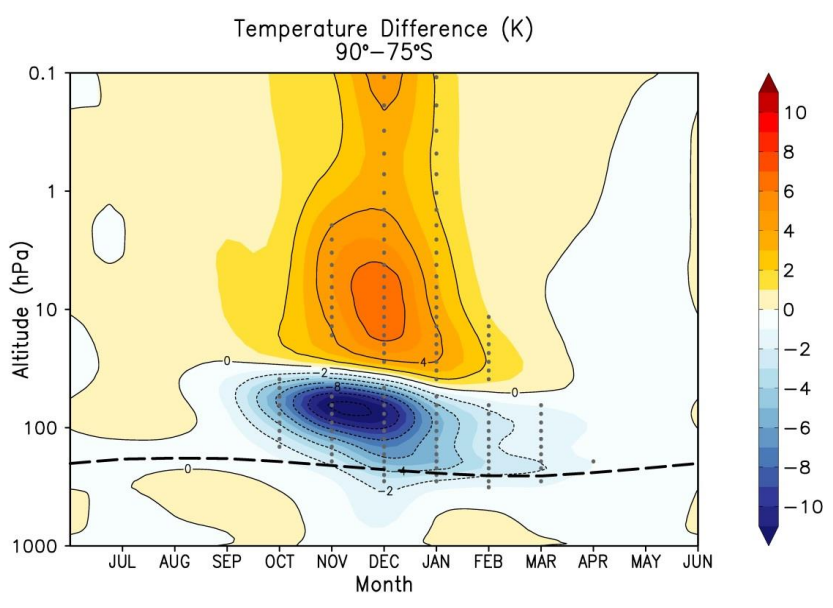

Figure 3. Zonal mean, monthly mean temperature difference between REF2000 and NHC, averaged over $90-75^{\circ} \mathrm{S}$. Contour intervals are $2 \mathrm{~K}$, solid/dashed contours represent positive/negative changes. Stippling denotes significance at the $95 \%$ confidence level. The bold dashed line signifies the tropopause height in the REF2000 simulation.

tion, but coincide with peak SH depletion, possibly indicating a link between Antarctic ozone depletion and $\mathrm{NH}$ dynamics. If this is a robust response to increased polar ozone depletion, it could be used as an early indicator for $\mathrm{NH}$ transport changes as stratospheric $\mathrm{Cl}_{\mathrm{y}}$ decreases throughout the 21 st century. It should be stressed that the effects beyond the vortex are the result of the model reaching a new equilibrium state and have been accumulated over previous years, and that heterogeneous processes within the vortex do not lead to mid-latitude ozone loss in the same month.

\subsection{Temperature, zonal wind, geopotential height and vertical circulation changes}

Figure 3 shows the monthly, zonal mean temperature difference between the two integrations averaged over $90-75^{\circ} \mathrm{S}$, plotted as a function of altitude and month. Modelled polar ozone loss leads to a strongly seasonal response. Cooling of the lower polar stratosphere begins in September when sunlight returns to the core of the polar vortex, and continues through until March. Maximum cooling occurs from November to December, during which time temperatures at $70 \mathrm{hPa}$ decrease by $12 \mathrm{~K}$. Strong cooling of the polar lower stratosphere resulting from ozone loss is consistent with observations (Thompson and Solomon, 2002; Roscoe et al., 2003) and idealised model studies (Gillett and Thompson, 2003; Manzini et al., 2003; Karpechko et al., 2010). There is no statistically significant change in temperature during the summer, in agreement with observations. While ozone loss causes the lower stratosphere to cool, the upper stratosphere warms, beginning in October and persisting through to January-February. Maximum warming occurs in December, when polar cap averaged temperatures increase by $>6 \mathrm{~K}$

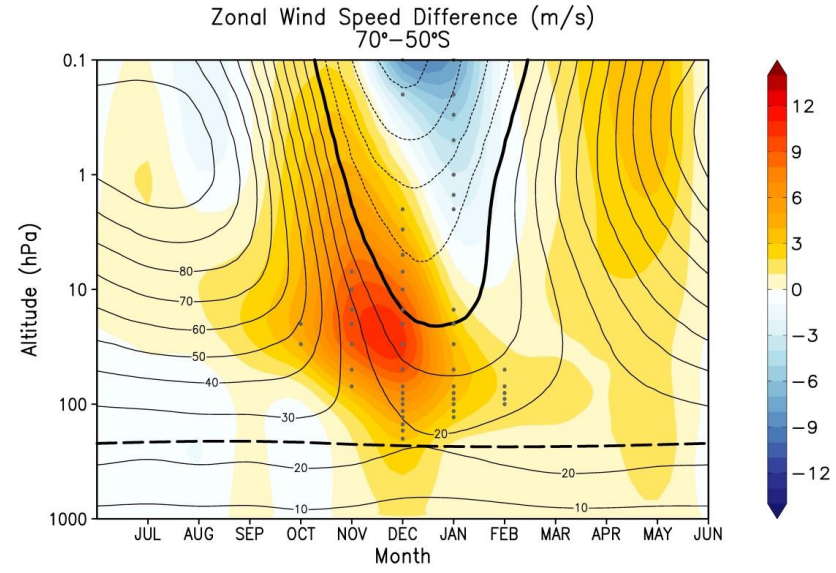

Figure 4. Zonal mean, monthly mean zonal wind REF2000 climatology (contours) and difference between REF2000 and NHC (shaded), averaged over $70-50^{\circ} \mathrm{S}$. Contour intervals are $10 \mathrm{~m} \mathrm{~s}^{-1}$; solid/dashed contours represent positive/negative changes. The $0 \mathrm{~m} \mathrm{~s}^{-1}$ contour is highlighted in bold. Stippling denotes significance at the $95 \%$ confidence level. The bold dashed line signifies the tropopause height in the REF2000 simulation.

at $10 \mathrm{hPa}$. The results presented by Thompson and Solomon (2002) extend up to $30 \mathrm{hPa}$, and therefore do not show the region of upper stratospheric warming modelled in this study. However, warming of the upper stratosphere is in agreement with observations presented by Young et al. (2013), and with a number of modelling studies that assess the impact of ozone loss above $30 \mathrm{hPa}$ (e.g. Shindell and Schmidt, 2004).

Figure 4 shows the impact of modelled polar ozone loss on the zonal mean and zonal wind, averaged over $50-70^{\circ} \mathrm{S}$. The temperature change due to polar ozone loss leads to a statistically significant acceleration of the modelled westerlies around Antarctica from mid-spring to late summer, and also causes the polar vortex to shift polewards. As with the temperature response, the zonal wind changes are highly seasonal, with no statistically significant changes during autumn and summer. As well as accelerating the polar vortex, the cooling due to polar ozone loss also causes the breakdown of the polar vortex to be delayed by approximately 2 weeks. For any given month, a delay in the transition from westerlies to easterlies is realised as an increase in the height of the zero wind line, highlighted in bold in Fig. 4 for the REF2000 integration. A delayed breakup of the polar vortex resulting from increased ozone loss is in good agreement with other studies (Waugh et al., 1999; Haigh and Roscoe, 2009; Karpechko et al., 2010; McLandress et al., 2010). The changes to zonal wind speed are not confined to the stratosphere, with a nonsignificant increase in westerly wind descending into the troposphere in December. The extension of the zonal wind response into the troposphere is also noted by other authors (e.g. Polvani et al., 2011).

Figure 5 shows the difference in geopotential height between the two integrations, averaged from 90 to $75^{\circ} \mathrm{S}$. Large 


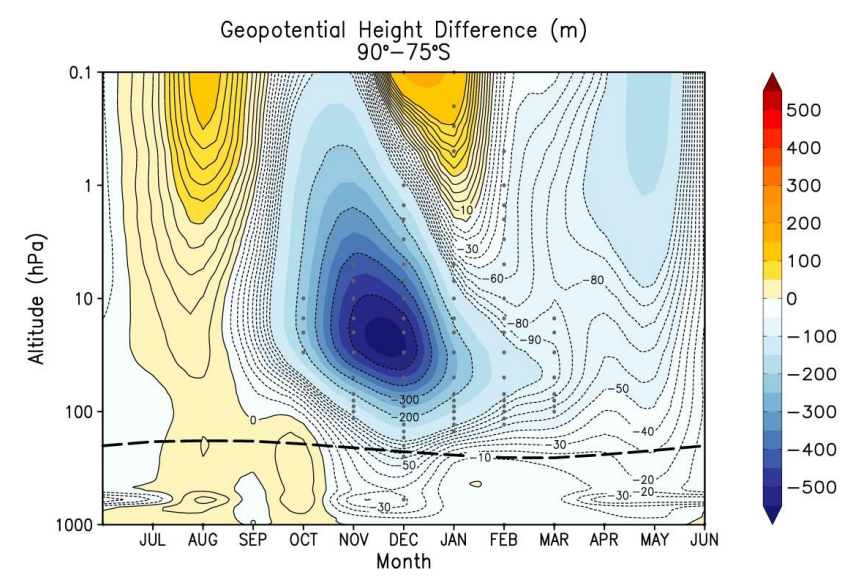

Figure 5. Zonal mean, monthly mean geopotential height difference between REF 2000 and NHC, averaged over $90-75^{\circ}$ S. Shaded contour intervals are $50 \mathrm{~m}$, while contour lines are every $10 \mathrm{~m}$ between 100 and $-100 \mathrm{~m}$ and $100 \mathrm{~m}$ outside of this range. Solid/dashed contours represent positive/negative changes. Stippling denotes significance at the $95 \%$ confidence level. The bold dashed line signifies the tropopause height in the REF2000 simulation.

negative changes of more than $200 \mathrm{~m}$ are modelled throughout the depth of the stratosphere from October to January, with statistically significant changes persisting through to March. The largest decreases occur in the lower stratosphere in November and December, during which geopotential height decreases of $>500 \mathrm{~m}$ are modelled. These changes are indicative of a stronger, colder polar vortex. Further to the stratospheric changes, decreased geopotential height anomalies are modelled to propagate down into the troposphere, highlighted in Fig. 5 by the $10 \mathrm{~m}$ contour intervals as the changes are not of the same order as those in the stratosphere. The geopotential height changes modelled here are in good agreement with other model studies (e.g. Gillett and Thompson, 2003) and observations (Thompson and Solomon, 2002).

Differences to the mean residual vertical circulation, $\bar{w}^{*}$, averaged over the polar cap $\left(90-75^{\circ} \mathrm{S}\right)$ are shown in Fig. 6, with negative changes indicating increased downwelling/reduced upwelling. Downwelling over the polar cap is increased from late spring to early summer, with statistically significant changes in November and December throughout the depth of the stratosphere. Increased downwelling at high southern latitudes has been noted in other model studies (e.g. Manzini et al., 2003; McLandress et al., 2010). The changes to the mean residual vertical velocity are strongly seasonal, and occur at the time when modelled stratospheric circulation over the polar cap changes from downwelling to upwelling.

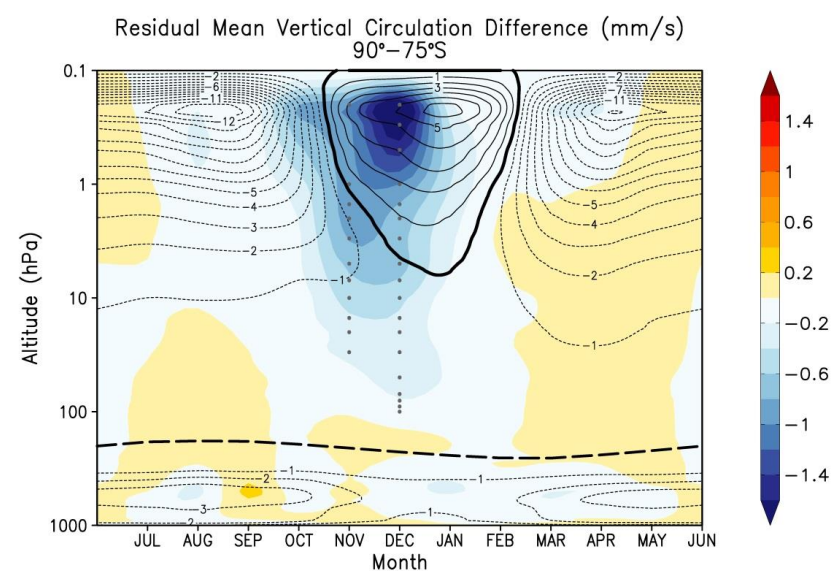

Figure 6. Zonal mean, monthly mean residual vertical velocity, $\bar{w}^{*}$, REF2000 climatology (contours) and difference between REF2000 and NHC (shaded) averaged over $90-75^{\circ} \mathrm{S}$. Contour intervals are $1 \mathrm{~mm} \mathrm{~s}^{-1}$, solid/dashed contours represent upwelling/downwelling respectively. The $0 \mathrm{~mm} \mathrm{~s}^{-1}$ contour is highlighted in bold. Stippling denotes significance at the $95 \%$ confidence level. The bold dashed line signifies the tropopause height in the REF2000 simulation.

\section{Physical mechanisms in the stratosphere}

In order to further investigate the stratospheric temperature differences between the two simulations, we calculate the dynamical and short-wave heating components of the temperature response to polar ozone loss. Short-wave heating rates are diagnosed directly from the model, and the difference between the two integrations is shown in Fig. 7a. In the lower stratosphere, short-wave heating rates decrease during austral spring and summer, with a maximum reduction of $>0.6 \mathrm{~K} \mathrm{day}^{-1}$ in November-December. The decrease in short-wave heating is coincident with the region of depleted ozone, and this is likely the dominant control, although changes to other radiatively important trace gases will play a role. Short-wave heating increases in November at $10 \mathrm{hPa}$, and this increase persists through time until late summer, descending in altitude during this period. This is coincident with an increase in ozone mixing ratios. It should be noted that while the magnitude of the lower stratospheric temperature changes is large, cooling occurs too late in the year to significantly affect modelled PSC formation. Any change in PSC frequency would significantly affect lower stratospheric water vapour mixing ratios, which would have an important radiative impact. However, dehydration differences due to PSC particle sedimentation between the two integrations are negligible, and so the effect of stratospheric water vapour differences between the two integrations is likely small.

Dynamical heating is not directly diagnosed by the model, and is calculated using the ageostrophic equation from 

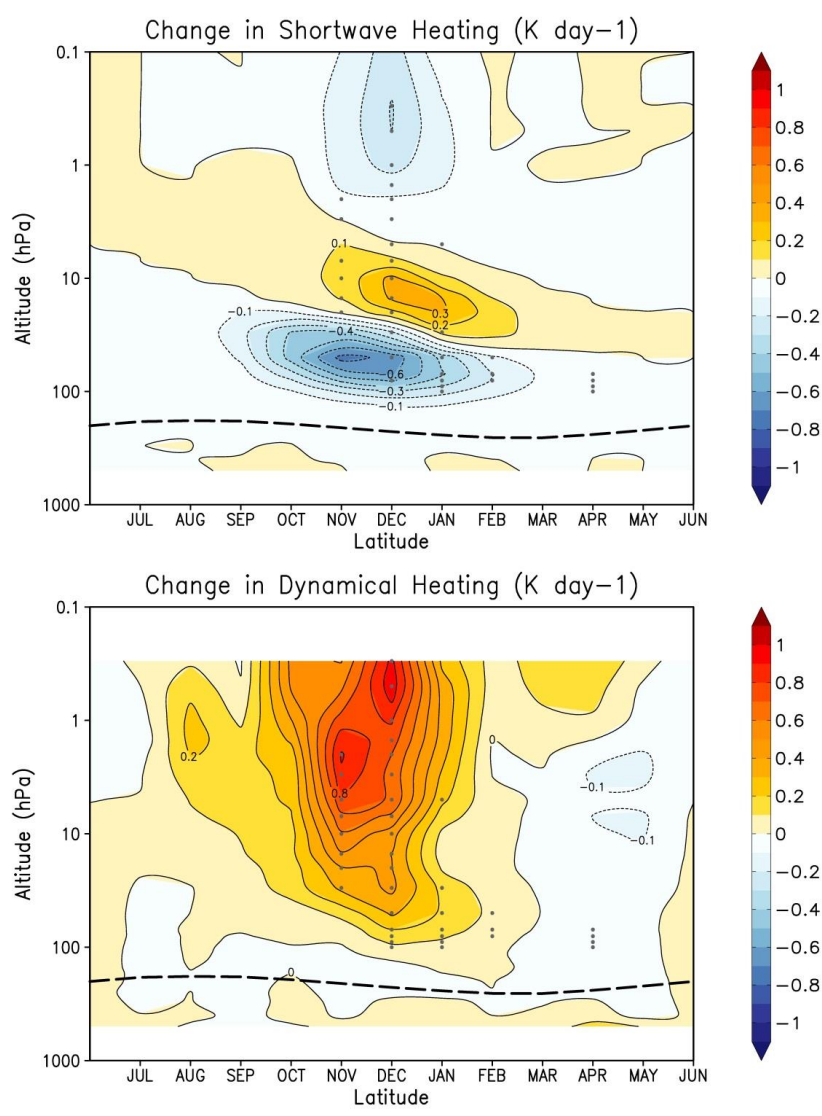

Figure 7. Zonal mean, monthly mean short-wave heating (top) and dynamical heating (bottom) differences between REF2000 and $\mathrm{NHC}$, averaged over $90-75^{\circ} \mathrm{S}$. Contour intervals are $0.1 \mathrm{~K} \mathrm{day}^{-1}$. Stippling denotes significance at the $95 \%$ confidence level. The bold dashed line signifies the tropopause height in the REF2000 simulation.

Dunkerton et al. (1981):

$\bar{Q}_{\mathrm{d}}^{\theta}=-\rho_{0}^{-1}\left\{\rho_{0}\left[\left(\frac{\bar{\theta}_{\varphi}}{a \bar{\theta}_{z}}\right) \overline{v^{\prime} \theta^{\prime}}+\overline{w^{\prime} \theta^{\prime}}\right]\right\}_{z}-\frac{1}{a} \bar{\theta}_{\varphi} \bar{v}^{*}-\bar{\theta}_{z} \bar{w}^{*}$

where $\bar{Q}_{\mathrm{d}}^{\theta}$ is the dynamical heating rate of the zonally averaged potential temperature, $\theta$ is the potential temperature, $\rho_{0}$ is the background density, subscripts $\varphi$ and $z$ denote the partial derivatives with respect to latitude and height respectively, $a$ is the radius of the earth $(6371 \mathrm{~km}), v$ and $w$ are the meridional and vertical wind components respectively and $\bar{v}^{*}$ and $\bar{w}^{*}$ are the meridional and vertical components of the mean residual circulation respectively. In order to compare with the short-wave heating rates from the model, the result is then converted into absolute temperature using

$\bar{Q}_{\mathrm{d}}=\bar{Q}_{\mathrm{d}}^{\theta}\left(\frac{p}{p_{0}}\right)^{R / C_{p}}$,

where $p$ is pressure, $p_{0}$ is surface pressure (assumed to be $1000 \mathrm{hPa}$ ), $R$ is the gas constant of air and $C_{p}$ is the spe- cific heat capacity. Figure $7 \mathrm{~b}$ shows the polar cap average difference in dynamical heating between the two simulations. There is a strong increase in dynamical heating during late spring and summer, extending throughout the depth of the stratosphere. This increase is statistically significant in November and December, and throughout the summer in the lowermost stratosphere.

The dipole in the temperature response to ozone loss can therefore be explained by a combination of changes to shortwave and dynamical heating. Decreased ozone mixing ratios lead to pronounced cooling of the lower stratosphere. This is to some extent mitigated by a small increase in dynamical heating below $10 \mathrm{hPa}$. The peak increase in temperature in the middle stratosphere is the result of an increase to both short-wave and dynamical heating. Above $10 \mathrm{hPa}$ there is little change to short-wave heating, and the increase in temperatures is almost solely due to increases in dynamical heating, consistent with large changes to $\bar{w}^{*}$ at these altitudes, but little change to ozone.

Changes to stratospheric temperatures lead to changes in long-wave heating rates. As we use time averaged data for this study it is not straightforward to fully close the heat budget, and so we do not explore these changes in any great detail. However, the strong cooling of the lower stratosphere leads to decreased emission of downward long-wave radiation, consistent with Grise et al. (2009). Averaged over the polar cap, this leads to a weak, non-significant cooling propagating down into the troposphere during December (Fig. 3). Tropospheric changes are explored further in Sect. 5. Cooling of the lower stratosphere increases the mid-latitude to pole temperature gradient, which drives the increased zonal wind speeds shown in Fig. 4 through thermal wind balance and also causes the polar night jet to shift poleward.

Changes to the mean residual vertical velocity (shown in Fig. 6) are a measure of changes to the BDC. Differences in Eliassen-Palm (EP) flux divergence between the two integrations, averaged over $50-70^{\circ} \mathrm{S}$, are shown in the upper panel of Fig. 8. Negative values represent decreased flux divergence, i.e. increased convergence, and indicate increased wave breaking. During mid to late spring there is a weak decrease in wave breaking, a result that is consistent with McLandress et al. (2010). The spring time decrease in EP flux divergence has received little study, and the mechanisms controlling it are poorly understood. From late spring to late summer wave breaking increases, starting in November at $\sim 1 \mathrm{hPa}$ and persisting through to February, decreasing in altitude with time. Increased wave breaking in the mid to high latitudes during summer drives increased downwelling over the polar cap (Fig. 6). Using Fourier transform analysis (not shown here) we are able to determine that it is predominantly resolved planetary waves that drive these changes, which is in agreement with other authors (e.g. McLandress et al., 2010).

It is important to determine whether the changes to wave breaking are the result of changes to the wave activity en- 


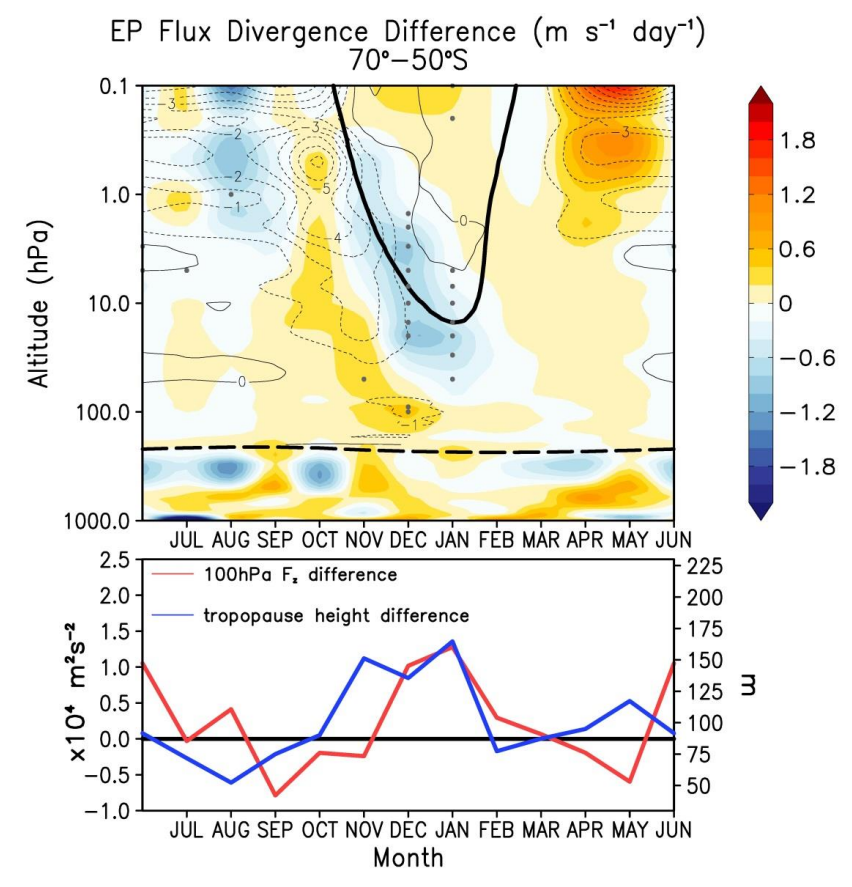

Figure 8. Zonal mean, monthly mean EP flux divergence REF2000 climatology (contours) and difference between REF2000 and NHC (shaded), averaged over $70-50^{\circ} \mathrm{S}$. Contour intervals are $1 \mathrm{~m} \mathrm{~s}^{-1} \mathrm{day}^{-1}$, solid/dashed contours represent positive/negative changes. Stippling denotes significance at the $95 \%$ confidence level. The zero wind line from REF2000 is highlighted in bold, while the bold dashed line signifies the tropopause height in the REF2000 simulation. The lower panel shows the zonal mean, monthly mean difference to the vertical component of the EP flux, $F_{z}\left(\times 10^{4} \mathrm{~m}^{2} \mathrm{~s}^{-1}\right)$, in red (left-hand axis), and the zonal mean, monthly mean difference to tropopause height $(\mathrm{m})$ in blue (righthand axis), both averaged over $70-50^{\circ} \mathrm{S}$.

tering the stratosphere or of alterations to the propagation of waves through the stratosphere. The $100 \mathrm{hPa}$ vertical component of the EP flux, which is proportional to the meridional heat flux $\left(\overline{v^{\prime} T^{\prime}}\right)$, can be used as a measure of upward propagating planetary wave activity entering the stratosphere from the troposphere. The lower panel of Fig. 8 shows the difference in the $100 \mathrm{hPa}$ vertical EP flux vector, $F_{z}$, between the two simulations, averaged over $50-70^{\circ} \mathrm{S}$, in red. During the spring there is a weak decrease in $F_{z}$ in the mid to high latitudes, while in the summer there is a strong increase over a similar latitude range. These changes coincide with the decrease/increase in wave breaking in the spring/summer modelled in the lower stratosphere, and are statistically significant in December and January. However, although $F_{z}$, and therefore wave driving, show slight decreases in October and November, wave breaking at $\sim 1 \mathrm{hPa}$ in November has increased. Also, large increases in $F_{z}$ are modelled in June, with no significant change to EP-flux divergence at that time, while the decrease in wave propagation in September-October is near zero but wave breaking
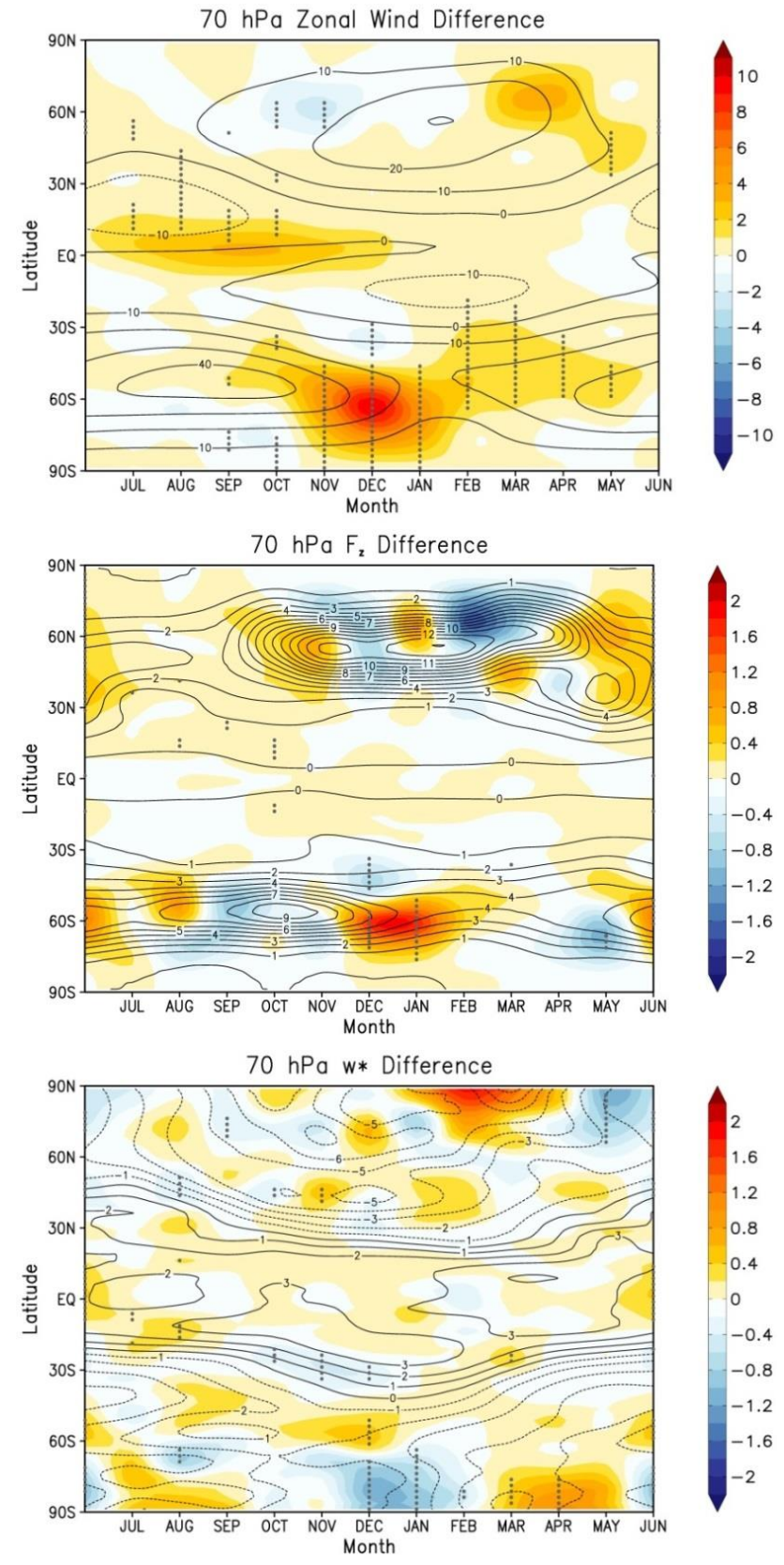

Figure 9. Zonal mean, monthly mean, zonal wind (top); vertical component of the EP flux vector, $F_{z}$ (middle); and residual vertical velocity, $\bar{w}^{*}$, (bottom) REF2000 climatology (contours) and difference between REF2000 and NHC (shaded), at $70 \mathrm{hPa}$. Contour intervals for the REF2000 climatology are $10 \mathrm{~m} \mathrm{~s}^{-1}$ (top), $1 \times 10^{4} \mathrm{~m}^{2} \mathrm{~s}^{-2}$ (middle) and $1 \mathrm{~mm} \mathrm{~s}^{-1}$ (bottom). Stippling denotes significance at the $95 \%$ confidence level.

is greatly reduced. Therefore, changes to wave propagation from the troposphere to the stratosphere are not likely to be the dominant control on the changes to wave breaking resulting, although they likely do play a role in the increased wave breaking modelled in December-January. 
Also shown in the lower panel of Fig. 8 are changes to tropopause height averaged over $50-70^{\circ} \mathrm{S}$, in blue. The largest tropopause height changes $(>125 \mathrm{~m})$ are modelled from November to January, and result from the cooling of the lower stratosphere due to ozone depletion and the resultant changes to the lapse rate. The summer time tropopause height changes occur together with the large increases to $F_{z}$ in December-January, and suggest a relationship between the two, although the tropopause height response leads the changes to $F_{z}$ by a month. As we compare two different equilibrium states it is difficult here to identify a causal link between changes to tropopause height and $F_{z}$. However, the two metrics respond in a consistent way, suggesting a relationship between tropopause height and the wave driving entering the stratosphere from the troposphere. For a more detailed discussion on the impacts of ozone depletion on tropopause height changes see Braesicke et al. (2013).

If changes to the wave driving propagating from the troposphere to the stratosphere play only a minor role in the changes to wave breaking, polar ozone loss must lead to alterations in how planetary waves are able to propagate through the stratosphere. Vertical planetary wave propagation is only possible through westerly winds, and is reduced when zonal wind speeds exceed a critical value, $U_{\mathrm{c}}$, such that a propagation window exists when the following condition is satisfied:

$0<u<U_{\mathrm{c}}$.

The increases in zonal wind speed in austral spring limit planetary wave propagation through the stratosphere by increasing westerly winds above the threshold $U_{\mathrm{c}}$. Conversely, the increase in height of the zero wind line and the delayed breakdown of the polar vortex, discussed above, allow planetary waves to propagate higher into the stratosphere and over a longer period of time in the summer. This is shown in Fig. 8, where decreased EP flux divergence occurs around the time of the descent of the zero wind line. This, combined with the changes to $F_{z}$ discussed above, results in statistically significant increases in wave breaking in the mid to high latitudes in December and January.

The link between changes to zonal wind speed, vertical planetary wave propagation and downwelling can be explored further by analysing latitude time sections at a set altitude in the lower stratosphere, as shown for $70 \mathrm{hPa}$ in Fig. 9. From September to November there is a weak negative correlation between zonal wind speed (Fig. 9a) and the vertical component of the EP flux vector (Fig. 9b). This is consistent with zonal wind speeds increasing above the critical value $U_{\mathrm{c}}$, preventing some planetary waves from propagating higher into the stratosphere. As planetary wave breaking deposits easterly momentum, the decrease in planetary wave propagation helps to strengthen the polar vortex. In this way a positive feedback is set up in spring such that increased westerlies lead to increased filtering of planetary waves, which results in decreased wave breaking and deposition of easterly
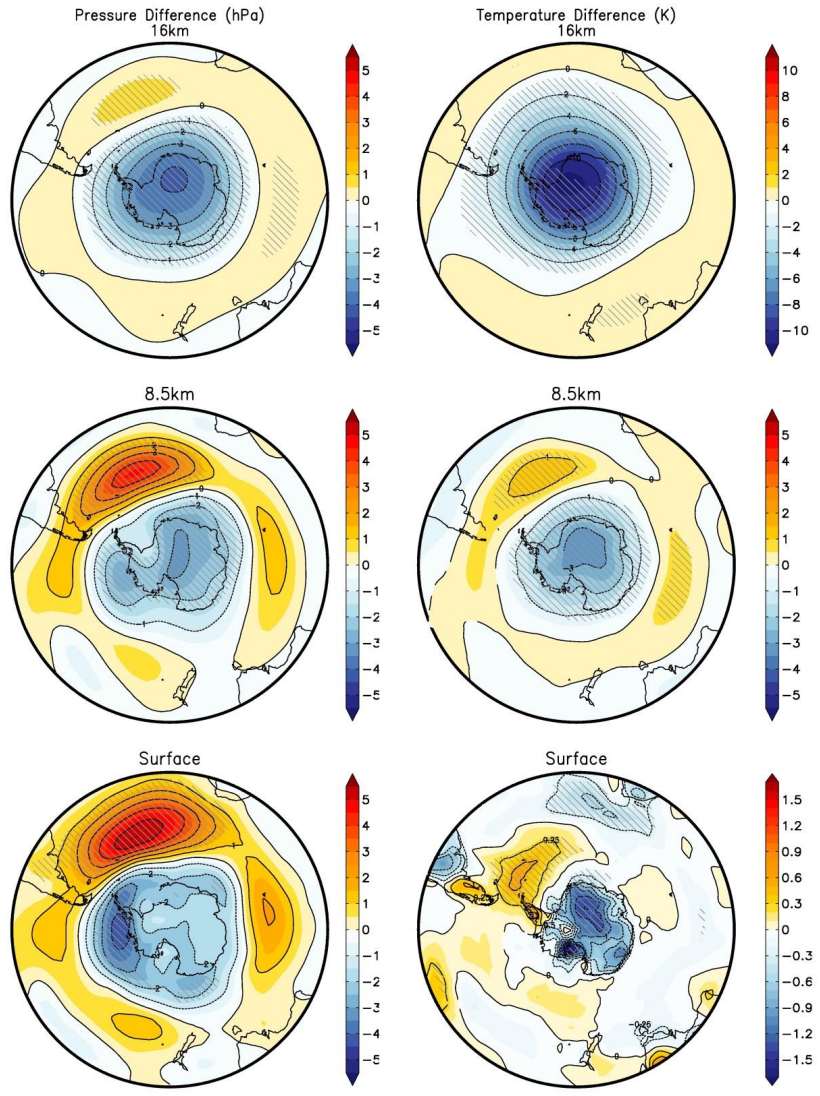

Figure 10. Stereographic plots of December pressure (left) and temperature (right) differences between REF2000 and NHC at $16 \mathrm{~km}$ (top), $8.5 \mathrm{~km}$ (middle) and the surface (bottom). Note the different scales for the temperature response at different altitudes. Hatching denotes significance at the $95 \%$ confidence level.

momentum, preventing the deceleration of the polar jet and causing it to persist for longer (consistent with the mechanism proposed by Orr et al., 2012a). However, the meridional heat flux and $\bar{w}^{*}$ differences are not significant at the $95 \%$ confidence level, and it is difficult to infer a causal relationship.

In summer, a much more robust relationship is evident. From November to January westerly wind speeds at 60 $80^{\circ} \mathrm{S}$ are greatly increased at $70 \mathrm{hPa}$ due to thermal wind balance and the delay of the breakup of the vortex, as discussed above. During December and January, across the same latitude range, the vertical propagation of planetary waves through this layer is enhanced. Increased propagation through the layer leads to increased wave breaking above, driving increased downwelling at $70 \mathrm{hPa}$, shown by changes to $\bar{w}^{*}$ (Fig. 9c). While the increased downwelling through the $70 \mathrm{hPa}$ layer occurs at the same time as the enhanced meridional heat flux, it does not occur at the same latitude range, unlike the changes in zonal wind speed and meridional heat flux. Instead it is displaced poleward of the region of enhanced vertical planetary wave propagation. In this 
stage of the vortex lifetime a negative feedback now operates between zonal wind speed and planetary wave propagation. Increased westerlies allow increased wave breaking, which results in the increase of deposition of easterly momentum, decelerating the vortex and ultimately causing it to collapse. This relationship also holds for regions where westerly wind speed decreases. In December, as the polar jet moves poleward, there is a decrease in westerly wind speed at $45-30^{\circ} \mathrm{S}$, which correlates to a region of decreased vertical planetary wave propagation, and a decrease in downwelling.

\section{Tropospheric changes and surface impacts}

As discussed in the previous sections, the temperature, zonal wind and geopotential height differences resulting from stratospheric ozone loss extend down into the troposphere, reaching the modelled surface in December. Figure 10 shows the impact of increased stratospheric ozone loss on December pressure and temperature at $16 \mathrm{~km}$ (in the lower stratosphere, $\sim 100 \mathrm{hPa}$ ), $8.5 \mathrm{~km}$ (at the tropopause, $\sim 250 \mathrm{hPa}$ ) and the surface. Statistically significant temperature decreases extend downwards from the lower stratosphere to the surface of the model. At $16 \mathrm{~km}$ the cooling, as much as $10 \mathrm{~K}$ in the core of the vortex, is strongly zonally symmetric, as is the cooling at $8.5 \mathrm{~km}$, although the magnitude is decreased. Associated with this is an increase in tropopause height by 300-500 m, resulting from a decrease in lower stratospheric temperatures and changes to the lapse rate (explored further in Braesicke et al., 2013). While the temperature response in the lower stratosphere and free troposphere is zonally symmetric, the surface temperature response shows a marked asymmetry. Most of the Antarctic continent cools by more than $0.5^{\circ} \mathrm{C}$, with statistically significant cooling of more than $1^{\circ} \mathrm{C}$ over the Ross Ice Shelf and much of East Antarctica. Conversely the Antarctic Peninsula warms by more than $0.5^{\circ} \mathrm{C}$. As the version of the model used in this study uses prescribed sea surface temperatures and sea ice, it is likely to damp the surface response. Despite this caveat, the asymmetric modelled surface response is in good agreement with observations (Thompson and Solomon, 2002) and numerous model studies (e.g. Gillett and Thompson, 2003).

Modelled ozone losses lead to a zonally symmetric reduction in pressure in the lower stratosphere, extending down from $16 \mathrm{~km}$ to the surface. Surface pressure decreases over the Antarctic continent, and increases north of $65^{\circ} \mathrm{S}$. This pattern closely resembles the positive phase of the Southern Annular Mode (SAM), and is in good agreement with other modelling studies. The surface response extends far beyond the Antarctic continent, and it is well known that the SAM influences SH storm tracks, precipitation and near surface winds over a large area of the SH (e.g. Thompson et al., 2011).

\section{Summary and conclusions}

We have presented results from an idealised model study using UM-UKCA to assess the impacts of lower stratospheric ozone loss on SH stratospheric circulation and climate. Two simulations were run, both using perpetual year 2000 boundary conditions. The first used a full stratospheric chemistry scheme, while in the second heterogeneous chemistry occurring on PSCs was suppressed. This resulted in two simulations, one of which models severe, high-latitude, spring time ozone depletion and one of which does not. In this way we quantify the effects of polar stratospheric ozone depletion on four key variables: temperature, zonal wind speed, geopotential height and polar downwelling. The method used in this study differs from those used in previous studies on the climatic impacts of ozone depletion and is well suited to studying the feedbacks of chemistry-climate and chemicaldynamical interactions in an idealised sense.

Through heterogeneous reactions occurring on the surfaces of PSCs, chlorine held within the reservoir species $\mathrm{HCl}$ and $\mathrm{ClONO}_{2}$ is converted into reactive species which deplete ozone through catalytic cycles when sunlight returns to the polar vortex in spring. The increased active chlorine causes lower stratospheric ozone to be depleted by more than $50 \%$ from September to January, with peak depletion of $75 \%$ from October to November. While this is in good agreement with observations and other modelling studies, we also model an increase in ozone mixing ratios between 30 and $10 \mathrm{hPa}$ from December to March due to changes in stratospheric dynamics. Despite also being modelled in other studies, this feature is not commonly included in studies using prescribed ozone fields as it lies above the top level of radiosonde measurements. However, due to the radiative impact of ozone, it is an important feature for understanding chemistry-climate interactions and feedbacks. Ozone changes extend beyond the spring time polar vortex. Despite global $\mathrm{Cl}_{\mathrm{y}}$ being constant between the two runs, zonal mean total column ozone is reduced at almost all latitudes, with equatorial total column ozone reduced by $15 \mathrm{DU}$. However, column ozone at $60^{\circ} \mathrm{N}$ is increased by up to $30 \mathrm{DU}$ throughout late spring and winter due to increased northward transport of ozone by a stronger BDC. If this feature is shown to be a consistent response to high-latitude polar ozone depletion, changes to total column ozone trends at this latitude may provide evidence for changes to the strength of the BDC as stratospheric $\mathrm{Cl}_{\mathrm{y}}$ decreases. Further work is required to determine the effects of stratospheric ozone depletion on NH total column ozone trends.

Polar ozone depletion produces a vertical dipole in the temperature response: while the lower stratosphere cools due to decreased short-wave heating, the middle and upper stratosphere warms due to a combination of dynamical heating (the dominant component) and increased short-wave heating at $\sim 10 \mathrm{hPa}$. Increased dynamical heating below $10 \mathrm{hPa}$ somewhat mitigates the short-wave cooling of the lower strato- 
sphere (consistent with Orr et al., 2012b). The cooling of the lower polar stratosphere increases the midlatitude to pole temperature gradient, causing an acceleration and poleward shift of the polar vortex, and delaying the breakup of the polar vortex. We demonstrate a relationship between zonal wind speed, upward propagating planetary wave activity as diagnosed by the vertical component of the EP flux vector, and mean residual vertical velocity. In spring increased zonal mean wind speeds limit vertical planetary wave propagation, inducing a positive feedback which strengthens further the polar vortex due to the decreased deposition of easterly momentum resulting from wave breaking. Conversely, in summer increased zonal wind speeds and the delayed breakup of the polar vortex allow planetary wave activity to propagate higher into the stratosphere for a longer period of time. This results in increased wave breaking, as diagnosed by decreased EP flux divergence, which drives increased downwelling over the pole throughout November and December. Our analysis indicates that changes to wave propagation from the troposphere to the stratosphere play only a minor role in the changes to wave breaking resulting from polar ozone depletion. The change in wave propagation is coincident with an increase in tropopause height in December and January, although there is no change in $F_{z}$ despite increased tropopause height in June.

Lower stratospheric ozone depletion also drives statistically significant tropospheric changes which extend down to the surface. In December, stratospheric ozone depletion causes surface pressure to decrease poleward of $\sim 60^{\circ} \mathrm{S}$, and increase from 60 to $30^{\circ} \mathrm{S}$ in a pattern resembling the positive phase of the SAM. Surface temperature is also affected, with significant cooling modelled over much of the Antarctic continent, and warming over the Antarctic Peninsula.

As ozone recovers over the 21 st century, the changes discussed in this paper will likely reverse. How ozone recovery and global warming will offset one another or combine to produce rapid change remains an important discussion.

Acknowledgements. We thank NCAS-CMS for modelling support. Model integrations have been performed using the UK National Supercomputing Service HECToR. J. Keeble, P. Braesicke and H. Roscoe thank NERC for support through grant NE/H024778/1. H. Roscoe also participated as part of the British Antarctic Survey's Polar Science for Planet Earth programme, also funded by the Natural Environment Research Council. We would also like to thank two anonymous reviewers for their comments, which helped improve aspects of the paper.

Edited by: M. Dameris

\section{References}

Arblaster, J. M. and Meehl, G. A.: Contributions of external forcings to Southern Annular Mode trends, J. Climate, 19, 28962905, doi:10.1175/JCLI3774.1, 2006.

Braesicke, P., Hurwitz, M. M., and Pyle, J. A.: The stratospheric response to changes in ozone and carbon dioxide as modelled with a GCM including parameterised ozone chemistry, Meteorol. Z., 15, 343-354, doi:10.1127/0941-2948/2006/0124, 2006.

Braesicke, P., Keeble, J., Yang, X., Stiller, G., Kellmann, S., Abraham, N. L., Archibald, A., Telford, P., and Pyle, J. A.: Circulation anomalies in the Southern Hemisphere and ozone changes, Atmos. Chem. Phys., 13, 10677-10688, doi:10.5194/acp-1310677-2013, 2013.

Brewer, A. W.: Evidence for a world circulation provided by the measurements of helium and water vapour distribution in the stratosphere, Q. J. Roy. Meteor. Soc., 75, 351-363, 1949.

Chipperfield, M. P.: Multiannual simulations with a threedimensional chemical transport model, J. Geophys. Res., 104, 1781-1805, 1999.

Dobson, G. M. B.: Origin and distribution of the polyatomic molecules in the atmosphere, Proc. R. Soc. London, A236, 187193, 1956.

Dunkerton, T., Hsu, C.-P. F., and McIntyre, M. E.: Some Eulerian and Lagrangian diagnostics for a model stratospheric warming, J. Atmos. Sci., 38, 819-843, 1981.

Eyring, V., Chipperfield, M. P., Giorgetta, M. A., Kinnison, D. E., Manzini, E., Matthes, K., Newman, P. A., Pawson, S., Shepherd, T. G., and Waugh, D. W.: Overview of the new CCMVal reference and sensitivity simulations in support of upcoming ozone and climate assessments and the planned SPARC CCMVal, SPARC Newsletter, 30, 20-26, 2008.

Farman, J. C., Gardiner, B. G., and Shanklin, J. D.: Large losses of total ozone in Antarctica reveal seasonal ClOx/NOx interaction, Nature, 315, 207-210, 1985.

Garcia, R. R. and Randel, W. J.: Acceleration of the Brewer-Dobson circulation due to increases in greenhouse gases, J. Atmos. Sci., 65, 2731-2739, doi:10.1175/2008JAS2712.1, 2008.

Gillett, N. P. and Thompson, D. W. J.: Simulation of recent Southern Hemisphere climate change, Science, 302, 273-275, doi:10.1126/science.1087440, 2003.

Grise, K. M., Thompson, D. W. J., and Forster, P. M.: On the role of radiative processes in stratosphere-troposphere coupling, J. Climate, 22, 4154-4161, doi:10.1175/2009JCLI2756.1, 2009.

Haigh, J. D. and Roscoe, H. K.: The final warming date of the Antarctic polar vortex and influences on its interannual variability, J. Climate, 22, 5809-5819, 2009.

Hewitt, H. T., Copsey, D., Culverwell, I. D., Harris, C. M., Hill, R. S. R., Keen, A. B., McLaren, A. J., and Hunke, E. C.: Design and implementation of the infrastructure of HadGEM3: the next-generation Met Office climate modelling system, Geosci. Model Dev., 4, 223-253, doi:10.5194/gmd-4-223-2011, 2011.

Karpechko, A. Y., Gillett, N. P., Gray, L. J., and Dall'Amico, M.: Influence of ozone recovery and greenhouse gas increases on Southern Hemisphere circulation, J. Geophys. Res., 115, D22117, doi:10.1029/2010JD014423, 2010.

Karpechko, A. Y., Backman, L., Thölix, L., Ialongo, I., Andersson, M., Fioletov, V., Heikkalä, A., Johnsen, B., Koskela, T., Kyrölä, E., Lakkala, K., Myhre, C. L., Rex, M., Sofieva, V. F., Tamminen, J., and Wohltmann, I.: The link between spring- 
time total ozone and summer UV radiation in Northern Hemisphere extratropics, J. Geophys. Res.-Atmos., 118, 8649-8661, doi:10.1002/jgrd.50601, 2013.

Lee, A. M., Roscoe, H. K., Jones, A. E., Haynes, P. H., Shuckburgh, E. F., Morrey, M. J., and Pumphrey, H. C.: The impact of the mixing properties within the Antarctic stratospheric vortex on ozone loss in spring, J. Geophys. Res., 106, 3203-3211, 2001.

Manzini, E., Steil, B., Brühl, C., Giorgetta, M. A., and Krüger, K.: A new interactive chemistry-climate model: 2 . Sensitivity of the middle atmosphere to ozone depletion and increase in greenhouse gases and implications for recent stratospheric cooling, J. Geophys. Res., 108, 4429, doi:10.1029/2002JD002977, 2003.

McElroy, M. B., Salawitch, R. J., Wofsy, S. C., and Logan, J. A.: Reductions of Antarctic ozone due to synergistic interactions of chlorine and bromine, Nature, 321, 759-762, 1986.

McLandress, C., Jonsson, A. I., Plummer, D. A., Reader, M. C., Scinocca, J. F. and Shepherd, T. G.: Separating the dynamical effects of climate change and ozone depletion. Part I: Southern Hemisphere stratosphere, J. Climate, 23, 5002-5020, doi:10.1175/2010JCLI3586.1, 2010.

Molina, L. T. and Molina, M. J.: Production of $\mathrm{Cl}_{2} \mathrm{O}_{2}$ from the selfreaction of the ClO radical, J. Phys. Chem., 91, 433-436, 1987.

Morgenstern, O., Braesicke, P., O’Connor, F. M., Bushell, A. C., Johnson, C. E., Osprey, S. M., and Pyle, J. A.: Evaluation of the new UKCA climate-composition model - Part 1: The stratosphere, Geosci. Model Dev., 2, 43-57, doi:10.5194/gmd-2-432009, 2009.

Morgenstern, O., Zeng, G., Abraham, N. L., Telford, P. J., Braesicke, P., Pyle, J. A., Hardiman, S. C., O'Connor, F. M., and Johnson, C. E.: Impacts of climate change, ozone recovery, and increasing methane on surface ozone and the tropospheric oxidizing capacity, J. Geophys. Res.-Atmos., 118, 1028-1041, doi:10.1029/2012JD018382, 2013.

Orr, A., Bracegirdle, T. J., Hosking, J. S., Jung, T., Haigh, J. D., Phillips, T., and Feng, W. H.: Possible dynamical mechanisms for Southern Hemisphere climate change due to the ozone hole, J. Atmos. Sci., 69, 2917-2932, 2012a.

Orr, A., Bracegirdle, T. J., Hosking, J. S., Feng, W. H., Roscoe, H. K., and Haigh, J. D.: Strong Dynamical Modulation of the Cooling of the Polar Stratosphere Associated with the Antarctic Ozone Hole, J. Climate, 26, 662-668, doi:10.1175/JCLI-D-1200480.1, 2012b.

Perlwitz, J., Pawson, S., Fogt, R. L., Nielsen, J. E., and Neff, W. D.: Impact of stratospheric ozone hole recovery on Antarctic climate, Geophys. Res. Lett., 35, L08714, doi:10.1029/2008GL033317, 2008.

Polvani, L. M., Waugh, D. W., Correa, G. J. P., and Son, S.-W.: Stratospheric ozone depletion: The main driver of 20th Century atmospheric circulation changes in the Southern Hemisphere, J. Climate, 24, 795-812, doi:10.1175/2010JCLI3772.1, 2011.

Roscoe, H. K., Colwell, S. R., and Shanklin, J. D.: Stratospheric temperatures in Antarctic winter: does the 40-year record confirm midlatitude trends in stratospheric water vapour?, Q. J. Roy. Meteor. Soc., 129, 1745-1759, doi:10.1256/qj.02.173, 2003.

Schoeberl, M. R. and Hartmann, D. L.: The dynamics of the stratospheric polar vortex and its relation to the springtime ozone depletions, Science, 251, 46-52, 1991.
Schoeberl, M. R., Lait, L. R., Newman, P. A., and Rosenfield, J. E.: The structure of the polar vortex, J. Geophys. Res., 97, 78597882, doi:10.1029/91JD02168, 1992.

Shindell, D. T. and Schmidt, G. A.: Southern hemisphere climate response to ozone changes and greenhouse gas increases, Geophys. Res. Lett., 31, L18209, doi:10.1029/2004g1020724, 2004.

Sigmond, M. and Fyfe, J. C.: Has the ozone hole contributed to increased Antarctic sea ice extent?, Geophys. Res. Lett., 37, L18502, doi:10.1029/2010GL044301, 2010.

Sigmond, M., Reader, M. C., Fyfe, J. C., and Gillett, N. P.: Drivers of past and future Southern Ocean change: Stratospheric ozone versus greenhouse gas impacts, Geophys. Res. Lett., 38, L12601, doi:10.1029/2011GL047120, 2011.

Sloan, C. L. and Pollard, D.: Polar stratospheric clouds: A high latitude warming mechanism in an ancient greenhouse world, Geophys. Res. Lett., 25, 3517-3520, 1998.

Solomon, S.: Stratospheric ozone depletion: A review of concepts and history, Rev. Geophys., 37, 275-316, doi:10.1029/1999RG900008, 1999.

Solomon, S., Garcia, R. R., Rowland, F. S., and Wuebbles, D. J.: On the depletion of Antarctic ozone, Nature, 321, 755-758, 1986.

Son, S.-W., Gerber, E. P., Perlwitz, J., Polvani, L. M., Gillett, N. P., Seo, K.-H., Eyring, V., Shepherd, T. G., Waugh, D., Akiyoshi, H., Austin, J., Baumgaertner, A., Bekki, S., Braesicke, P., Bruhl, C., Butchart, N., Chipperfield, M. P., Cugnet, D., Dameris, M., Dhomse, S., Frith, S., Garny, H., Garcia, R., Hardiman, S, C., Jockel, P., Lamarque, J. F., Mancini, E., Marchand, M., Michou, M., Nakamura, T., Morgenstern, O., Pitari, G., Plummer, D. A., Pyle, J., Rozanov, E., Scinocca, J. F., Shibata, K., Smale, D., Teyssedre, H., Tian, W., and Yamashita, Y.: Impact of stratospheric ozone on Southern Hemisphere circulation change: a multimodel assessment, J. Geophys. Res., 115, D00M07, doi:10.1029/2010JD014271, 2010.

SPARC: SPARC assessment of stratospheric aerosol properties (ASAP), Tech. Rep. WMO-TD No. 1295, WCRP Series Report No. 124, SPARC Report No. 4, Berrieres le Buisson, Cedex, 2006.

Thompson, D. W. J. and Solomon, S.: Interpretation of recent Southern Hemisphere climate change, Science, 296, 895-899, 2002.

Thompson, D. W. J., Solomon, S., Kushner, P. J., England, M. H., Grise, K. M., and Karoly, D. J.: Signatures of the Antarctic ozone hole in Southern Hemisphere surface climate change, Nat. Geosci., 4, 741-749, doi:10.1038/ngeo1296, 2011.

Toon, O. B., Hammill, P., Turco, R. P., and Pinto, J.: Condensation of $\mathrm{HNO}_{3}$ and $\mathrm{HCl}$ in the winter polar stratospheres, Geophys. Res. Lett., 13, 1284-1287, 1986.

Tuck, A. F.: Synoptic and chemical evolution of the Antarctic vortex in late winter and early spring, 1987, J. Geophys. Res., 94, 11687-11737, doi:10.1029/JD094iD09p11687, 1989.

Waugh, D. W. and Polvani, L. M.: Stratospheric polar vortices, in: The Stratosphere: Dynamics, Transport, and Chemistry, Geophys. Monogr. Ser., Vol. 190, edited by: Polvani, L. M., Sobel, A. H., and Waugh, D. W., 43-57, AGU, Washington, D. C., doi:10.1029/2009GM000887, 2010.

Waugh, D. W., Randel, W. J., Pawson, S., Newman, P. A., and Nash, E. R.: Persistence of the lower stratospheric polar vortices, J. Geophys. Res., 104, 27191-27201, 1999. 
Waugh, D. W., Oman, L., Kawa, S. R., Stolarski, R. S., Pawson, S., Douglass, A. R., Newman, P. A., and Nielsen, J. E.: Impacts of climate change on stratospheric ozone recovery, Geophys. Res. Lett., 36, L03805, doi:10.1029/2008GL036223, 2009.

WMO: World Meteorological Organization Global Ozone Research and Monitoring Project - Report No. 52, Scientific Assessment of Ozone Depletion: 2010, 2011.
Young, P. J., Butler, A. H., Calvo, N., Haimberger, L., Kushner, P. J., Marsh, D. R., Randel, W. J., and Rosenlof, K. H.: Agreement in late twentieth century southern hemisphere stratospheric temperature trends in observations and CCMVal2, CMIP3, and CMIP5 models, J. Geophys. Res., 118, 605-613, doi:10.1002/jgrd.50126, 2013. 